\title{
Regional Linkage in Tourism Development of Vietnam
}

\author{
Van Hoa Hoang, Manh Dung Tran, Thi Van Hoa Tran, Vu Hiep Hoang \\ National Economics University, Vietnam
}

Correspondence: dungtm@neu.edu.vn; Tel: +84947120510

\begin{abstract}
This study was conducted to investigate the status of regional linkage in tourism development in in the Midlands and Northern Mountains of Vietnam. The data was collected from a survey of 755 people, including officials from State management bodies in charge of tourism, officials and staffs at tourism resorts, tourism firms, tourism scientists and tourists. In addition, we conducted 10 group discussions, interviewed 30 State tourism agency officials and tourism firms in the Midland and Mountainous provinces of Vietnam. The results show that tourism development in Vietnam in general and the Northwest region in particular is extremely fragmented, not yet forming a regional linkage; Regional and national tourism development programs are just formalistic. The main cause of the situation is the limited regional integration policy in Vietnam, the lack of appropriate regional governance mechanisms and inactive participation of the private sector in regional integration. Based on the findings, we propose a tourism sector linkage model; besides, policy implications are given for fulfilling the linkage policy in the Midlands and Northern Mountains area.
\end{abstract}

Keywords: Midlands and Northern Mountains, tourism linkage, Vietnam.

\section{Introduction}

Since the 1990s, the Vietnamese Government has advocated regional economic development, employed "zoning plan" to promote regional coordination. In 2012-2013, the Government approved the master plan for socio-economic development for 6 regions up to 2020 including: i) the North Central and Central Coast; ii) the Central Highlands; iii) the Mekong River Delta; iv) the Southeast; v) the Red River Delta; and vi) in the Midlands and Northern Mountains. However, these plans are not implemented effectively in practice. In Vietnam, "region" is not an administrative-economic level. With a population of nearly 100 million in 2017 , covering an area of 310,060 square kilometers, Vietnam is divided into 63 provinces and cities. In terms of territorial organization, the economy is organized based on "provincial" unit. In this organizational structure, provinces are independent in terms of administrative and budgetary management. 63 provinces in Vietnam have different social and economic conditions but basically have the same economic structure. The economic activity of the provinces is quite isolated, each province strives to implement its own socio-economic targets and there is almost no "horizontal" relationship among provinces. Thus, in Vietnam there are 63 comparable and similar "independent" economies (Tran, 2016). Such a system of territorial economic organizations is revealing the some major weaknesses such as i) waste of resources due to not being able to promote the advantages of economies of scale; ii) unfair competition among provinces; iii) obstructing the trend of modern economic development which is to form and expand the chain of links and production networks.

Therefore, in the context of Vietnam, the regional economic space has not yet been established and there is no close linkage among provinces. The basic constraints of regional economic policy in Vietnam are (i) the importance of regional economic development as a rule of market economy development is not clear; (ii) the socio-economic functions of each region are not clearly defined for 
policy and institutional design; not synchronous among branch plans, regional and local planning; (iii) lack of linkage implementation among regional ministries and localities in decision-making on the principle of regional economic development. There are many reasons for the limitations of regional development in Vietnam such as i) linkage has not become a developmental mindset. In policy as well as practical guidance, local leaders have not really paid much attention to regional integration in developing the socio-economic strategy, the role of the private sector has not been clearly defined; ii) no regional administrative organization; iii) lack of linkages in the planning among provinces, cities in a region, low quality of planning, assignment and coordination of space development is relatively ineffective and lack of regional linkage content.

The issue of linkage coordination between provinces in each region as well as among different regions is a "bottleneck" that needs to be addressed to improve regional economic efficiency. Recently, the study on the organization of the tourist territory in Vietnam has begun to be studied. Tourism activities cannot develop effectively without full attention to the spatial dimension (territory) of tourism. It is a spatially integrated system of tourism objects and related services based on the optimal use of tourism resources, infrastructure and technical facilities and other determinants to achieve the highest economic, social and environmental performance towards sustainable development (Pham, 2014).

The Midlands and Northern Mountains includes 14 provinces in the North of Vietnam, including Hoa Binh, Son La, Dien Bien, Lai Chau, Yen Bai, Phu Tho, Lao Cai, Tuyen Quang, Ha Giang, Bac Kan, Thai Nguyen, Cao Bang, Lang Son and Bac Giang. The whole region covers an area of $95,254.4 \mathrm{~km} 2$ (accounting for $28.6 \%$ of the country's area). The population is 11.9 million in 2016 , mainly ethnic minorities (64\%); this is also the poorest economic area in the country which has the rate of poor households of $26 \%$, which is three times higher than the national average, with the number of poor districts accounting for $70 \%$ of the country (Northwest Steering Committee, 2017). This area is mostly mountains with the terrain is perilous and highly isolated which makes it the most dangerous area in Vietnam. However, this is also the region with the most tourism potential in Vietnam with many tourist resorts, national tourism center, historic and scenic majestic. Since 2018, tourism has been identified as a spearhead economic sector to promote the region's socio-economic development and poverty reduction. In recent years, this area has started to form a number of tourism linkage development programs. However, such programs have not reached the required efficiency. Therefore, it is essential to firstly promote tourism linkage, and secondly propose the most appropriate tourism linkage model to ensure sustainable tourism development in association with socio-economic development in this area.

\section{Literature Review}

\subsection{Regional Linkage}

\section{International studies}

Since the 1950s, research on regional economics and regional linkage has been firstly proposed. Perroux (1955) and Hirschman (1966), Pack and Saggi (1999); Giroud and Scott-Kennel (2006) studied regional and regional economic models and established two major models including polar/growth center model and regional cluster/network model.

\section{Polar/growth center model}

The concept of the "growth pole" was firstly introduced by Perroux (1955), emphasizing the role of a highly innovative and pervasive sector that played a key role in the development process. Perroux said that growth and development cannot occur everywhere at the same time and that they are only present at some point with varying intensity. They spread through different channels with different effects on the economy. Therefore, it is necessary to focus on the most dynamic economic activity on a regional growth pole, thereby promoting the development of other regions in a connected 
space system and form a set of interconnected economies between the growth pole and the surrounding area. Such concentration and diffusion are considered as a growth pole. According to Boudeville (1966), regional growth poles are a dynamic set of sectors in urban areas and are conducive to the development of economic activities throughout the region. These intermediate poles will continue to have a spreading effect on peripheral areas; and thus in the long run will achieve balanced regional and national growth.

An approach to spatial linkage in regional development is similar to the theory of Friedman (1966) about growth pole as central-peripheral model. Friedman (1966) argued that central areas are relatively abundant in capital and where innovations arise, while the peripheries are relatively redundant and dependent on the center; economic growth exists through the emergence of a hierarchical system of highly developed and closely related cities and towns.

\section{Regional cluster/network model}

This approach is proposed by Douglass (1978), in a "bottom-up" manner in development planning and has the following characteristics as i) relatively small geographic scale; ii) have a high degree of autonomy in decision-planning and decision-making, based on community involvement and collective action at the local level; iii) diversification of agricultural work, including both agricultural and non-agricultural activities, with emphasis on small-scale rural industrialization; iv) there is a linkage between industrial functions between urban and rural areas, based on local economic resources and structures; and v) ongoing use and evaluation of local resources and technology.

The concept of networks is based on three basic foundations of i) diversity in rural-urban linkages; ii) interactions between villages and towns, forming networks of varying degrees within and outside the region; and iii) focused clusters with strong interactions and linkage are better than one growth pole due to economies of scale and diversity (Douglass, 1978).

\section{Vietnamese Studies}

The most prominent research on regional integration in Vietnam is the "Study on Policy and Recommendations for Regional Economic and Regional Linkage Development (Central Economic Commission, 2015). The study has raised international experiences on regional economic development and regional integration, to provide an overview of the regional economic development and regional integration and propose some solutions for regional economic development and regional linkages in Vietnam.

Nguyen and Nguyen (2007), Tran (2016), and Vu (2017) highlighted the situation of regional linkage in Vietnam. These authors argue that regional linkages in Vietnam are still limited, have not yet formed regional governance institutions, each province has a small economic size, not yet formed a chain linkage. Ngo and $\mathrm{Vu}(2015)$ analyzed three development linkage factors in the key economic region: economic development linkage, infrastructure development linkage (transport, electricity, water); linkage to solve environmental pollution and human resource development linkage. However, the key economic areas still mainly developed based on quantity, not forming regional economic space.

Tran (2016) analyzed and assessed activities related to coastal provinces in Central Vietnam. There are many limitations in terms of regionalization in Vietnam, such as the lack of awareness of the need for regional linkages and the idea of regional integration in socio-economic development. $\mathrm{Vu}$ (2017) emphasized that regional linkage in Vietnam is still voluntary, less based on scientific and practical arguments, lack of motivation for stakeholders, lack of close linkages between localities, and a lack of proper regional institutional governance.

\subsection{Regional Linkage in Tourism Development}

\section{International Studies}


The issue of regional integration in tourism has been raised and focused in the context of new developments in regional competition and changes in the tourism industry such as the development of information technology, internet, and tourism demand of new consumers. According to Mills and Law (2004), internet is changing the structure of the tourism industry by changing entry barriers, revolutionizing distribution channels, facilitating price transparency and competition; as the results, enhancing business performance. Many scholars have argued that theoretical basis of regional linkage in tourism derives from Porter's (1985) destination strategy, Gilbert (1984)'s conceptions of tourism state and goods or the concept of dynamic specialization and frequent innovation of Poon (1994).

In the field of cluster linkage, Anderson et al. (2004) argued that the formation of close cooperative relationships or alliances between subjects is important to enhance competitiveness and promote tourism linkage. Considering the destination as a particular type of tourism, many studies have highlighted the need for cooperation and linkages (Gunn, 1997). Achieving high levels of linkage, with differentiated products and services based on frequent innovation, is a strategy for increasing the competitiveness of tourism destinations in a sustainable way, for the benefit of the local community. Recently, tourism linkages have moved from a competitive-based approach to a collaborative approach (Baggio et al., 2013; Mariani and Kylanen, 2014) in the direction that tourism destinations are promoted, marketed, and traded as a joint effort (Wang \& Shaul, 2008).

As tourism firms engage more deeply in regional, domestic and international networks, the cooperation and maintenance of relationships within the business network becomes necessary to enhance competitive efficiency (Erkus-Otzurk and Eraydın, 2010; Plummer et al., 2006).

In general, studies suggest that regional linkage is not only a requirement for tourism development in a given period but is also an indispensable option for tourism development. International studies on regional integration can provide useful theoretical and practical basis for regional studies in Vietnam.

\section{Vietnamese Studies}

In the context of Vietnam, there have been a number of articles on tourism links recently published in scientific journals and conference proceedings. The content of these articles includes some of the following key issues.

First, the views, objectives and content of the tourism linkage.

$\mathrm{Vu}$ (2017), Tran (2016) have raised their views on tourism linkages: equality, mutual benefit; linkage based on voluntary spirit; linkages are designed into specific projects and programs with clear objectives. Ha (2017) has developed 6 principles: observance, voluntary, consensus, equality, mutual benefit, sharing. Similarly, Pham (2014) also concretizes 3 principles of equality, volunteering, designing into projects, programs in tourism linkage.

Ha (2017) suggested the tourism linkage target is improving the efficiency of economic growth, ensuring the satisfaction of tourists, building tourism brand competition, establishing common resources of whole region, forming the key national tourist area and tourist route. Pham (2014) has set long-term goals to exploit and promote effectively the potentials and strengths of each region; the short-term target is to prioritize investment in key areas such as the development of tourism infrastructure, the connection of "destination" with key tourist destinations of the region, developing tourism products, training human resources.

$\mathrm{Vu}$ (2017), Tran (2016) outlined the content of linkages: redistribution of productive forces; adjust tourism development planning; to build synchronously the inter-provincial transport infrastructure; set up unified tourist space; joint training and development of human resources; to mobilize investment capital and develop a common policy mechanism for the whole region; coordinate tourism promotion. Ha (2014) emphasized on the content of tourism linkage product development. Nguyen (2016) proposes that the associated content should include the development of 
strategies, planning and policies for tourism development; coordinated by provinces to develop effective linkage mechanisms; travel linkage need to strengthen both horizontal links and vertical links.

Second, solutions for enhancing tourism linkage.

Tran (2015), Nguyen (2015), Do (2015) have proposed some recommendations: planning regional tourism, setting up the organizational structure of the management of the tourist area; enhancing horizontal and vertical link management; promotion and development of tourism brand; mobilizing resources in linking tourism promotion and advertisement; tourism product development and quality management of tourism products.

\subsection{Tourism Linkage of the Midland and Northern Mountain}

So far, there are very few in-depth studies on tourism linkages in this area, mainly some articles in the Northwest tourism conferences.

$\mathrm{Ha}$ (2017) has proposed some solutions to develop tourism products in the province of Phu Tho - Yen Bai - Lao Cai. Do (2015) refers to four tourism product groups suitable for the northern mountainous region such as: i) nature tourism and adventure sports; ii) product group exploring and experiencing the life of ethnic minority communities; iii) tourism product group and agro-ecotourism product group.

Tran (2016), Ha (2017), Nguyen (2017), Hoang and Tran (2016) analyzed the current status of regional linkage in the Northwestern Vietnam and proposing solutions for the development: i) establishing effective linkage mechanism, establishing the Steering Committee for regional tourism linkage, building regional tourism fund; ii) provincial linkage to develop tourism products bearing the identity of each region and each locality; iii) focus on promoting inter-regional tourism; iv) regional planning of tourism sites and routes of each province and the whole region.

In summary, prior studies on regional and tourism linkage in Vietnam have initially assessed the situation and proposed some policies for linkages. However, research on tourism linkages has some limitations such as not clearly explained policies for tourism linkage development zone; the theoretical model has not been established as a basis for implementation in accordance with the conditions in Vietnam in general, the Midlands and Northern Mountains in particular.

\section{Research Methodology}

\subsection{Data Collection}

Data were collected by interviewing people relating to management, deployment and service recipients including official in state bodies in tourism, tourism resorts, tourism firms, scientists, and tourists. Based on literature review and interview results, questionnaires are designed basing on the Likert of 5 scales and sent to the above people. 1,000 questionnaires have been sent and the feedback is 766. In which, 11 questionnaires are removed from the final sample because of lacking major information and containing outliers. In consequence, 755 is the final sample, accounting for $75.5 \%$ feedback, and presented in Table 1 as below:

Table 1. Descriptive Analysis of Respondents

\begin{tabular}{lrrrrrrr}
\hline \multicolumn{1}{c}{ Respondents } & $\begin{array}{c}\text { Tuyen } \\
\text { Quang }\end{array}$ & $\begin{array}{c}\text { Ha } \\
\text { Giang }\end{array}$ & Phu Tho & Lao Cai & Hanoi & Total \\
\hline State Agencies in Tourism & 12 & 24 & 56 & 57 & 36 & $\mathbf{1 8 5}$ \\
Tourism Resorts & 24 & 30 & 14 & 14 & 9 & $\mathbf{9 1}$ \\
Tourism Firms & 33 & 36 & 22 & 41 & 51 & $\mathbf{1 8 3}$ \\
Scientists & 24 & 9 & 14 & 7 & 6 & $\mathbf{6 0}$
\end{tabular}




\begin{tabular}{lrrrrrrr} 
Tourists & 45 & 48 & 50 & 38 & 55 & $\mathbf{2 3 6}$ \\
& Total & $\mathbf{1 3 8}$ & $\mathbf{1 4 7}$ & $\mathbf{1 5 6}$ & $\mathbf{1 5 7}$ & $\mathbf{1 5 7}$ & $\mathbf{7 5 5}$ \\
\hline
\end{tabular}

The contents of questionnaires include the impact levels of tourism services, current conditions, current situations, linkage styles, roles of related parties, evaluation, solutions and others relating to regional linkage in the areas of midlands and mountains in the context of Vietnam.

\subsection{Data Processing}

Based on data collected, both primary and secondary data, we use statistical analysis for describing the current situations of the topic research. Then we synthesize, analyze and discuss the topic research of regional linkage in tourism development in the areas of midlands and mountains. Based on the current situations of the regional linkage, we propose a model and recommendations for improving the research topic in Vietnam.

\section{Results and Discussions}

\subsection{Deployment of Tourism Development Programs}

Since 2008, a number of tourism development programs have been established in this area, typically: i) "tourism linkage in eight provinces of Northwest expansion area"; ii) "tourism linkage through the Viet Bac heritage site". In addition, other provinces in the region have bilateral, multilateral and interregional tourism linkage.

Program of tourism linkage development in 8 provinces of Northwest expansion area

In 2008, eight provinces (Lao Cai, Yen Bai, Ha Giang, Lai Chau, Phu Tho, Hoa Binh, Son La and Dien Bien) have signed cooperation agreements on tourism development, including: collaborative rules, modes, and contents. With the support and technical advice of the EU project, cooperation activities of tourism development in those 8 provinces focused on 4 main areas: i) Policy mechanism; ii) product development; iii); promotion; and iv) human resource development.

(i) The 8 provinces have formed a general coordination mechanism, consisting of Steering Committee (provincial leaders), Permanent Committee (leadership of the Department of Culture, Sports and Tourism) and the assisting team (leaders and departmental staff of the Department of Culture, Sports and Tourism). The Board meets once a year, the Permanent Committee meets once a year, the assisting team meets twice a year. Management mechanism: The Steering Committee operates under the mechanism in which the head of the Executive Board rotating each year to review and evaluate the results of cooperation activities in the year and work out plans for the following year. To promote tourism linkage development activities, tourism development teams in each province have also been established: Tourism Product Development Working Group, Marketing Working Group, Human Resources Development Working Group.

(ii) Eight provinces have initially assigned and cooperated to develop tourism products according to the specific conditions of each province. For example, Phu Tho Province continues to promote the promotion of spiritual tourism along the Red River, tourism products serving international tourists to travel by river, visiting the program "Hat Xoan Lang Co" associated with the typical cultural tourism. Yen Bai Province focuses on developing Western tourism products in $\mathrm{Mu}$ Cang Chai and Nghia Lo, Van Chan districts; eco-tourism in Thac Ba lake; continue to cooperate with Phu Tho - Lao Cai to develop cultural tourism products along the Red River. Lao Cai province develops new tourism products such as discovering the heritage road of terraced rice culture in the Northwest in $\mathrm{Sa} \mathrm{Pa}$, Bat Xat and Bac Ha districts; highland market; Spiritual Travel along the Red River. Ha Giang province focuses on promoting the construction of outstanding tourism products, such as Dong Van stone plateau, Hoang Su Phi terraced fields. Hoa Binh province focuses on 
exploiting eco-tourism products of the Hoa Binh lake bed area in association with spiritual tourism and community tourism.

(iii) Eight provinces have coordinated to organize promoting tourism events, introducing tourism products and community tourism advantages of the region. Many activities have been implemented in the framework of cooperation such as organizing Northwest tourism fair; Organizing travel booths at international travel fairs; held a press conference introducing Northwest Tourism; Organizing the festival of culture, sports and tourism of the Northwest. These provinces have initially coordinated the construction of promotional tools for tourism in the region such as the Common tourism brand of the Northwest expansion area - the first unified tourism brand in Vietnam including logo and slogan, a guidebook for tourism in both English and Vietnamese languages; build a website at http://dulichtaybac.vn.

(iv) Provinces have implemented training courses for community tourism resource trainers; Organizing training courses to improve the quality of local tourism human resources; Organizing tour guides and tour guides to assess the professional qualifications and professional skills of tour guides and interpreters.

\section{Program of tourism linkage "through the Viet Bac heritage site"}

The program of tourism linkage development "through the Viet Bac heritage sites" includes six provinces of Bac Kan, Cao Bang, Ha Giang, Lang Son, Thai Nguyen and Tuyen Quang. The content of the linkage includes: promotion of awareness of tourism development; focusing on developing specific tourism products of each locality; building tours, tourist routes; market development, promotion of tourism; Development of human resources for tourism. In the period of 2006 - 2020, the six provinces are committed to continuing to work together to find the optimal solutions for the rational exploitation of available tourism resources, to improve the quality and diversification of tourism products, especially the inter-regional products, overcome the limitations of each locality.

The program of tourism linkage "through the Viet Bac heritage sites" has also established a steering mechanism, established a Steering Committee (composed of leaders of the six provinces), Standing Committee (including leaders of cultural departments sports and travel). Every year, provinces organize tourism events in provinces with many exciting and attractive activities, attracting the attention of travel firms and investors.

In addition to the above linkage programs, the provinces in the Midlands and Northern Mountains have implemented many bilateral and multilateral cooperation programs such as i) cooperating with the Vietnam Tourism Association to develop and implement a responsible tourism development strategy in the Northwest; collaborate on community tourism development, adventure tourism, exploring tourism; Cooperation in tourism promotion, marketing and marketing for tourism in the Northwest; ii) Co-operation between provinces in the region and major tourism centers in Vietnam (Hanoi, Ho Chi Minh City, and Red River delta provinces, Southern provinces). These include coordinating the propagation and promotion of tourism, jointly tours linkage, coordinating the training of human resources in tourism, attending tourism events, rotating the organization of programs, travel events.

Some provinces have strengthened their regional tourism linkage with the provinces of the Northeast, Yunnan (China), Thailand and Laos. For example, Dien Bien province initially developed tourism linkage with Chiang Rai (Thailand); coordinated with Phong Xa Ly, Udom Xay, Luang Prabang (Laos) to develop tourism cooperation activities. Lao Cai province cooperates to develop interregional, inter-regional and inter-regional tourism products in conjunction with Con Minh (Lao Cai) - Lao Cai - Hanoi - Hai Phong - Quang Ninh (Vietnam) Economic Corridor.

\subsection{Evaluations of Tourism Development Programs}

\section{Achievements}


First, the tourism development cooperation programs have initially overcome the division in tourism in each province, forming an inter-regional tourism linkage, creating conditions for expanding tourism linkages between the provinces in the region with some tourist centers in the country, promoting tourism linkage with Southeast Asian countries.

Second, the tourism linkage of the region is becoming more and more intensive, attracting the participation of many provinces in the region, enhancing cohesion in some tourism activities. Awareness of the importance of tourism linkage development has been increasingly enhanced, especially the staff of tourism management at local levels.

Third, activities within the framework of linkage programs have promoted the propaganda and promotion of the land, people, culture, tourism potentials and strengths of the provinces in the region. Tourism images in the Midlands and Northern Mountains have been more widely advertised both domestically and internationally.

Fourth, through the organization of festivals, many customs, habits, cultural traditions have been restored. Some provinces have formed and developed the type of community tourism, both exploiting the potential of local tourism as well as generating income and improving the lives of the poor.

Fifth, the quality of tourism services has been improved, many tours and tourism links are formed and put into effective exploitation. Many featured tourist products are built by linking the construction of tours, routes, destinations.

Sixth, the tourism development cooperation program has contributed to the promotion of tourism business. Visitor arrivals to the provinces increased by an annual average of more than $20 \%$ in the 2011-2017 period.

\section{Weaknesses}

First of all, tourism-related programs in this area have not yet formed a linkage between tourism, mainly horizontal cooperation between provincial authorities, territorial space links and inter-sectoral links. There is no coordination, close linkage with tourism associations and tourism business enterprises.

Second, most of the tourism linkage programs are mainly linked to promotion, emphasis on hosting events, exchanges, exchanging information; have not really paid attention to supervising and administering the implementation of linked contents. The content of linking specific product building, human resource training, planning, investment etc., are less focused or not implemented.

Third, some provinces have not focused on developing regional tourism products, less interested in developing new products. There is still overlap between the provinces, especially the community tourism products.

To assess the status of tourism linkage in the Midland and Northern Mountainous provinces, we conducted a survey of 755 people, including officials in the state management agencies in tourism, tourism businesses, scientists and tourists. Survey results are shown in the following table.

Table 2. Average point of assessment of the content of tourism development in the Midlands and Northern Mountains area

\begin{tabular}{cccccc}
\hline $\begin{array}{c}\text { Officials } \\
\text { in state } \\
\text { bodies in } \\
\text { tourism }\end{array}$ & $\begin{array}{c}\text { Officials } \\
\text { in } \\
\text { tourism } \\
\text { resorts }\end{array}$ & $\begin{array}{c}\text { Tourism } \\
\text { firms }\end{array}$ & Scientists & Tourists & Overall \\
\hline
\end{tabular}

1. The facts of linkage development of tourism strategies, planning and policies

- Provincial links on regional tourism development strategies

- Provincial links on regional tourism development plan

$\begin{array}{lllllll}2.98 & 3.09 & 3.14 & 2.77 & 3.28 & 3.11 \\ & & & & & & \\ 2.78 & & 2.97 & 3.11 & 2.98 & 3.11 & 3.00\end{array}$




\begin{tabular}{|c|c|c|c|c|c|c|}
\hline & $\begin{array}{l}\text { Officials } \\
\text { in state } \\
\text { bodies in } \\
\text { tourism }\end{array}$ & $\begin{array}{l}\text { Officials } \\
\text { in } \\
\text { tourism } \\
\text { resorts }\end{array}$ & $\begin{array}{l}\text { Tourism } \\
\text { firms }\end{array}$ & Scientists & Tourists & Overall \\
\hline $\begin{array}{l}\text { - Provincial links on regional tourism } \\
\text { development promotional policy }\end{array}$ & 2.66 & 2.90 & 2.92 & 2.86 & 3.08 & 2.90 \\
\hline \multicolumn{7}{|c|}{ 2. The facts of linkage development of tourism products } \\
\hline $\begin{array}{l}\text { - Linkage to develop the tourism } \\
\text { products for the whole region }\end{array}$ & 2.93 & 3.29 & 3.03 & 2.92 & 3.19 & 3.08 \\
\hline $\begin{array}{l}\text { - Linkage to develop the typical } \\
\text { tourism products of each sub-region }\end{array}$ & 2.91 & 2.99 & 3.06 & 2.98 & 3.26 & 3.07 \\
\hline $\begin{array}{l}\text { - Linkage to develop the typical } \\
\text { tourism products of each province }\end{array}$ & 2.90 & 2.75 & 2.99 & 2.87 & 3.17 & 2.99 \\
\hline $\begin{array}{l}\text { - Linkage to develop the tourism } \\
\text { service chain of the whole region }\end{array}$ & 2.73 & 2.88 & 2.92 & 2.82 & 3.15 & 2.93 \\
\hline $\begin{array}{l}\text { - Linkage to develop the tourism } \\
\text { routes }\end{array}$ & 2.84 & 2.81 & 2.98 & 2.91 & 3.20 & 2.99 \\
\hline \multicolumn{7}{|c|}{ 3. The facts of linkage development of tourism promotion } \\
\hline $\begin{array}{l}\text { - Linkage to develop the common } \\
\text { website }\end{array}$ & 2.90 & 2.97 & 3.08 & 2.91 & 3.24 & 3.06 \\
\hline $\begin{array}{l}\text { - Linkage to develop the common } \\
\text { brand }\end{array}$ & 2.53 & 2.85 & 2.84 & 2.65 & 3.11 & 2.83 \\
\hline - Linkage to establish the tourism fairs & 2.99 & 2.99 & 3.04 & 2.88 & 3.14 & 3.04 \\
\hline $\begin{array}{l}\text { - Linkage to share and provide tourism } \\
\text { information }\end{array}$ & 2.93 & 3.08 & 3.19 & 2.95 & 3.09 & 3.06 \\
\hline
\end{tabular}

Note: 1 being the lowest score, and 5 being the highest score.

Data in Table 2 reveal that average score of the surveyed people on the status of linkage content of the provinces in the region on tourism development strategies, planning and policies; links on the development of tourism products; and the promotion of tourism is very low, only 2.9 to 3.11 . Similarly, the average score of intra-regional and inter-regional linkages, linkages between destinations and links to foreign countries is relatively low, ranging from 2.83 to 2.9.

Fourthly, funding for tourism promotion and promotion is still limited, lack of binding mechanism and funding mechanism to organize inter-regional tourism activities; tourism activities are not carried out professionally. Many provinces do not have effective promotional tools and are not able to carry out major promotion programs at local and international tourism centers.

Fifthly, tourism-related programs have not yet developed suitable regional mechanisms and policies. It has not established a common governance framework for coordination across the region. Tourism activities are still self-contained in each locality. Therefore, the association results are limited, the fragmentation in tourism is still quite popular.

According to the survey, 358 out of 755 people (47.42\%) agreed that linkages in this area do not have clear coordination mechanism between provinces.

\section{Recommendations}

\subsection{Models of Regional Linkages in Tourism Development}

As mentioned above, Vietnam has not yet established a regional management structure (including some provinces) under the central government and there are no regional councils. Therefore, in order to effectively link tourist areas, it is necessary to build a model for tourism linkage development.

In terms of organization, Tourism Steering Committee for the Midlands and Northern Mountains was established by the Government, consisting of leaders from the Ministry of Culture, 
Sports and Tourism, the Ministry of Planning and Investment Finance, Vietnam Tourism Association, the State Steering Committee for Tourism, representatives of the People's Committee and tourism associations in 14 provinces in the region. The Regional Steering Committee is not an intermediary level between the central and provincial governments, but the lead agency playing an important role as the "conductor" in the regional tourism administration. The regional Steering Committee is decentralized to direct the settlement of issues related to the management of tourism resources and the organization of tourism development in accordance with the planning.

This will be the first model of tourism management in Vietnam. This model will implement the following forms of linkage: i) vertical linkages between the central government and the provincial governments, within provinces (provincial and district governments, communes); ii) horizontal links between localities in the region, links between regional centers for tourism development; iii) linkage between enterprises, shown in the following figure.

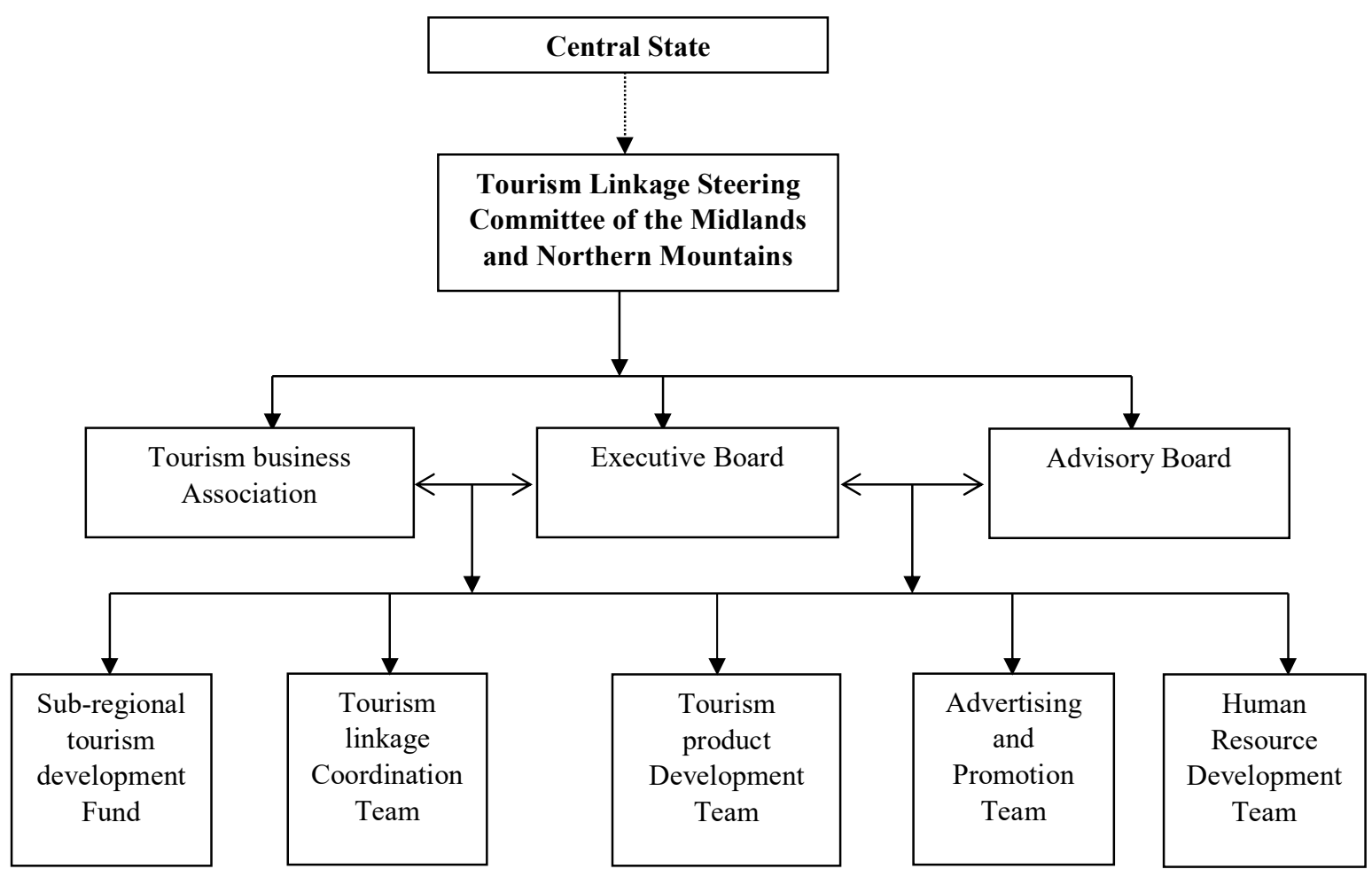

Figure 1. Organizational Structure of Tourism Linkage Mechanism in the Midlands and Northern Mountains of Vietnam

The main task of the Northwest Tourism linkage Steering Committee is to formulate the orientation for regional tourism development, solve related issues that cannot be solved by the provincial level. The specific tasks of the Northwest Tourism linkage Steering Committee include: i) Developing and implementing the strategy and planning for tourism development in the region and sub-region; ii) Developing projects to link tourism development; iii) Directing and coordinating tourism development programs and plans of sub-regions and regional provinces; iv) Making decision on measures and raising the resources of localities, organizations and individuals for tourism linkage development in the region; v) inspecting and urging localities to carry out activities related to tourism development in the region. 
The Executive Board is a standing body of the Northwest Tourism linkage Steering Committee, including representatives from the Departments of Culture, Sports and Tourism of the provinces, tourism associations and a number of enterprises. The specific tasks of the Steering Committee are: i) To advise the Steering Committee on the organization of cooperative activities among stakeholders to coordinate, study and support the management and development cooperation activities, regional tourism; ii) To assist the Steering Committee in promoting co-operation with sponsors, localities, businesses and communities; iii) To advise the Steering Committee to establish a network of provinces and other stakeholders; iv) To advise the Steering Committee in consultation with partners on issues related to planning and linking regional and sub-regional tourism development, priorities in the regional and sub-regional tourism development program.

The Advisory Board is composed of reputable scientists, representatives of some tourism managers and representatives of a number of tourism associations and businesses. The Advisory Board has the function of proposing and advising the Steering Committee on contents related to sustainable tourism development; to carry out consultancy, judgment and social expertise activities.

The Steering Committee for tourism development in the Midlands and Northern Mountains area will set up specialized teams with the following specific tasks:

(i) Human resource development team: consulting to build personnel strategy, organizational structure of personnel; reviewing and assessing tourism human resources in the area; planning and implementing training and fostering the human resources of tourism in the region.

(ii) Advertising and Promotion team: advising and organizing the implementation of tourism promotion activities in the region; formulating programs and plans for tourism promotion activities; schemes and activities related to tourism; Coordinating and guiding provinces and enterprises to promote tourism products and services.

(iii) Tourism product development team: advising the establishment of tourism product development strategies, planning tourism products and content of each product; Researching and developing new products.

(iv) Tourism linkage coordination team is responsible for advising the Steering Committee and the Executive Board on the implementation and coordination of tourism activities in sub-regions and provinces to formulate tourism development programs and plans for the sub-region; supervise and guide the provinces on activities related to tourism in the region.

(v) Sub-regional tourism development Fund is formed from state budget funds, business contributions, tourism fees and other funding sources; to make plans for spending on tourism promotion activities; supporting market research and development of tourism products; supporting for training and fostering tourism human resource development.

The survey results also showed that 691 out of 755 respondents $(91.53 \%)$ said that it is necessary to build a regional coordination organization in the Midland and Northern Mountains area.

Table 3. The need to establish a tourism coordination organization in the Midlands and Northern

\begin{tabular}{lcccccc}
\multicolumn{9}{c}{ Mountains area } \\
& $\begin{array}{c}\text { Completel } \\
\text { unnecessa } \\
\text { ry }\end{array}$ & $\begin{array}{c}\text { Unnecessa } \\
\text { ry }\end{array}$ & $\begin{array}{c}\text { Neutr } \\
\text { al }\end{array}$ & $\begin{array}{c}\text { Necessar } \\
\text { y }\end{array}$ & $\begin{array}{c}\text { Very } \\
\text { necessar } \\
\text { y }\end{array}$ & Total \\
\hline No. of people surveyed & $\mathbf{1}$ & $\mathbf{4}$ & $\mathbf{5 9}$ & $\mathbf{4 0 7}$ & $\mathbf{2 8 4}$ & $\mathbf{7 5 5}$ \\
Officials in state agencies in tourism & 1 & 2 & 17 & 105 & 60 & 185 \\
Officials in tourist resorts & - & - & 8 & 58 & 25 & 91 \\
Tourism Business & - & 2 & 7 & 89 & 85 & 183
\end{tabular}




\begin{tabular}{|c|c|c|c|c|c|c|}
\hline Scientist & - & - & 7 & 41 & 12 & 60 \\
\hline Tourist & - & - & 20 & 114 & 102 & 236 \\
\hline \multicolumn{7}{|l|}{ Structure of necessity (\%) } \\
\hline \multirow{3}{*}{$\begin{array}{l}\text { No. of of people surveyed (\%) } \\
\text { Officials in state management agencies in } \\
\text { tourism }\end{array}$} & & & & & & 100.0 \\
\hline & 0.13 & 0.53 & 7.81 & 53.91 & 37.62 & $\mathbf{0}$ \\
\hline & 0.54 & 1.08 & 9.19 & 56.76 & 32.43 & $\begin{array}{c}100.0 \\
0\end{array}$ \\
\hline Officials in tourist resorts & - & - & 8.79 & 63.74 & 27.47 & $\begin{array}{c}100.0 \\
0\end{array}$ \\
\hline Tourism Business & - & 1.09 & 3.83 & 48.63 & 46.45 & $\begin{array}{c}100.0 \\
0\end{array}$ \\
\hline Scientist & - & - & 11.67 & 68.33 & 20.00 & $\begin{array}{c}100.0 \\
0 \\
100\end{array}$ \\
\hline Tourist & - & - & 8.47 & 48.31 & 43.22 & $\begin{array}{c}0.0 \\
0\end{array}$ \\
\hline
\end{tabular}

\subsection{Policies of Regional Linkage}

(1) Complete the regional economic policy and regional linkage in the socio-economic development strategy in Vietnam

The government should review the socio-economic zoning to ensure a proper economic structure and spatial planning of national and regional space. The delimitation of the area should ensure that each area performs certain functions in socio-economic development. For instance, in some areas, economic growth is the main task; in some other areas, ecological preservation and resource conservation are main tasks; while the others need to ensure balance between economic development and political and social stability. The delimitation of socio-economic area should follow some basic scientific principles by clearly defining authority of regional governance; resolutely abolish the situation of closed state of administrative in each province.

(2) Enhance the role of tourism associations, tourism enterprises in the implementation of tourism linkage development

Associations of tourism enterprises have an important role as a social organization connecting tourism enterprises, consulting local governments on tourism development policies. It is a bridge between the business community and the local government. However, the role of tourism associations and tourism enterprises in the Northwestern region is significantly weak and passive in policy dialogue with government. Some provinces have not established tourism business associations. Therefore, it is necessary to enhance the role of tourism organizations, associations and enterprises. Provincial governments should create conditions for local tourism business associations to come into being and operate.

(3) Establish and complete the development of regional linkage planning in tourism development in Midlands and Northern Mountainous areas

It is necessary to develop a master plan for tourism development in the Midlands and Northern Mountains in the period of 2020-2030, in association with the socio-economic development planning to renovate the way of elaborating planning and formulating mechanisms for management and implementation of planning. Planning must ensure systematic, consistent and long-term vision; promote community and business roles, in line with market principles. It is used to review and supplement the tourism planning of provinces in accordance with the planning of tourism in the whole region, paying attention to specific nuances of regional and sub-regions, continuing to complete the planning of tourism in unplanned provinces.

(4) Define the contents of regional tourism linkages 
Establish regional tourism development planning, jointly design typical tourism products for the whole region and each sub-region in the development of tourism; encourage the promotion of tourist sites at regional and sub-regional levels; combine the construction and improvement of the transport system and the tourist infrastructure, to build regional and sub-regional tourist development funds; associate training and human resource development.

(5) Complete transportation systems and regional tourism service establishments

Upgrade the transportation system in the Midland and Northern Mountainous areas, expeditiously complete the transportation infrastructure projects for the bordering provinces; continue investing in the construction of new routes such as the 4C National Road of Ha Giang - Dong Van, the 4D National Road of Ban Phiet - Sin Ten intersection, National Road 32 of Deo Ke - Tu Le to connect the inter-provincial tourist routes.

Concentrate in investment in a number of tourist cities, form the central tourist growth pole of the whole region, such as $\mathrm{Sa} \mathrm{Pa}$ (Lao Cai), Dong Van stone plateau (Ha Giang province) Dien Bien (Dien Bien province), Moc Chau (Son La province). Visitors from major centers such as Hanoi, Ho Chi Minh City, Da Nang, Ha Long, to major tourism centers in the region and spread to other provinces. As such, these poles will become the center for distribution of visitors, centers of travel services, accommodation, souvenir production, human resources training center of the whole region. These thriving growth poles will become the locomotives of the entire cruise ship.

(6) Develop tourism product and regional and sub-regional tourist route in the Northwest

Linkage to build regional tourism products, including: nature and ecological tourism, mountain resort tourism, ethnic cultural tourism, cultural beliefs tourism to the roots, historical tourism: study the history over periods.

Linkage to build up tourist routes in the whole regional and sub-regional level: Da river subregion (provinces of Hoa Binh - Son La - Dien Bien - Lai Chau); Red - Lo River sub-region (Phu Tho - Yen Bai - Lao Cai, Tuyen Quang, Ha Giang); Northeastern region (Bac Giang, Thai Nguyen, Lang Son, Bac Kan, Cao Bang); Linkage to build up tourist routes with domestic tourism routes (Hanoi, Red River delta and other tourism centers); Linkage to build up cross-border tourism routes: tourism routes from Thailand - Myanmar - the ancient capital Luang Pra Bang - Dien Bien - Sa Pa - Hanoi. Linkage to coordinate and build up transnational tourist routes with China such as Hanoi - Lao Cai Hong Ha - Kunming; Hanoi - Ha Giang - Chau Van Son - Kunming; Cao Bang - Guangxi; Lang Son Nanning; cooperate with China to implement the program "one destination, two countries", "one destination, two cities"; build up a tourist route Hanoi - Vientiane (Laos); carry out tours of exploring and learning the culture and history of Laos and Vietnam.

(7) Linkage to advertise and promote regional and sub-regional tourism

Linkage to strengthen the information system for the promotion of the region and each subregion as well as building its own website. Website should be developed in many languages that meets the requirements of tourism promotion of the whole region, sub regions and localities. In addition to the website, it is suggested to promote the effectiveness of publicity, other online tools, such as social networking tools (facebook, instagram, youtube); Digital Content: Developing digital content through articles, images and videos on tourism in the Northwest. Joint publishing of regional, sub-regional publications: travel guides, hand-book. Build up general information database, regularly update regional and sub-regional tourist information. Improve the capacity and professionalism and efficiency of organizing and participating in tourism fairs. Strength the role of the private sector in promoting tourism. Promote the application of information technology and network of all hotels in the whole region with the provincial Department of Culture, Sports and Tourism with international border gates. 
(8) Linkage to establish training program for tourism human resources development; scientific and technological application linkage, and tourism businesses linkage

The Steering Committee of the whole region and the Executive Board of sub-regions closely coordinate with the provincial departments of Culture, Sports and Tourism, tourism enterprises, universities and colleges to provide essential training courses for managers and tourism staffs. The State should supports in the development of tourism faculties in universities in the region such as Tay Bac University (in Son La province), Hung Vuong University (in Phu Tho province), Tan Trao University (in Tuyen Quang province), Thai Nguyen University (in Thai Nguyen province) to become a professional tourism training center for the whole region; give priority to training and selection of ethnic minority children to work in tourist resorts; build a model of firms - universities to coordinate human resource training in tourism so as to combine training with the use of laborers; establish training organization that meets the requirement of Vietnam Tourism Occupational Standards.

In short, regional and sub-regional connectivity is one of the breakthroughs for tourism in the Midlands and Northern Mountain area. In order to have effective linkage and sustainable tourism development, a number of solutions need to be synchronized, including the development of regional and sub-regional linkages, overcoming administrative barriers. The combination of tourism and socioeconomic development is of great importance to promote tourism potential, contributing to promote socio-economic development in the Midlands and Northern Mountain area.

\section{Acknowledgement}

This research is the output of the theme of study on policies, solutions and design of area and sub area linkages in development of North-West of Vietnam, coded KHCN-TB.22X/13-18.

\section{References}

1. Anderson, J. C., Hakansson, H. \& Johanson, J. Dyadic business relationships within a business context, Journal of Marketing, 1994, 58(4), 1-15.

2. Asian Development Bank. Regional and sub-regional program links - Mapping the links between ASEAN and the GMS, BIMP-EAGA, and IMT-GT, 2013.

3. Baggio, R., Scott, N. \& Cooper, C. Network science - a review with a focus on tourism, Annals of Tourism Research, 2010, 37, 802-827.

4. Behrens, K., Thisse, J. Regional economics: A new economic geography perspective, Regional Science and Urban Economics, 2007, 37, 457-465.

5. Boudeville, J. R. Problems of regional economic planning, Edinburgh University Press, 1996.

6. Central Economic Committee. Summary report of research projects, policy proposals for regional economy, regional linkage. Meeting of Vietnam government, December 2015.

7. Central Economic Committee. Proceedings of an international symposium: Linkages in the process of economic restructuring and transformation of growth models in Vietnam, 2016.

8. Douglass, M. Cultural theory, Boston: Little, Brown \& Co, 1978.

9. Erkus-Otzurk, H. \& Eraydin, A. Tourist destination governance: practice, theory and issues, Annals Tourism Research, 2010, 38(4), 1300-1321.

10. Friedman, M. The methodology of positive economics, Essays in Positive Economics, University of Chicago Press, 1966.

11. Gilbert, M. Quantitative methods in tourism economics, A Springer Company, 1984.

12. Giroud, A. \& Scott-Knennel, J. MNE linkages in international business: A framework or analysis, International Business Review, 2009, 55, 369-398.

13. Gunn, C. A. Vacationscape, Developing tourist areas, Washington, DC: Taylor \& Francis, 1997. 
14. Ha, V.S. Potentials and solutions for regional linkage in developing Northwest regions, National Conference, Labour Publishing House, Vietnam, 2017.

15. Hirschman, A. The strategy of economic development, New Haven, Yale University, 1958.

16. Hoang, V.H. and Tran, H.S. Sustainable Tourism Linkage Development in the Northwest, Proceedings of the International Conference on Sustainable Tourism - the Role of Enterprises and Institutions, National Economic University, October. 2016.

17. Kinh, V.T. - Parnwel, M.J.G. Tourism in South East Asia, Routledge, London and New York, 1993.

18. Lea, J. Tourism and Development in the third world, Routledge, New York, 1998.

19. Lowson, F. and Baud, B. Tourism and Recreation Development. The Architec Lural London, 1977.

20. Le, A.V. Some basic theoretical issues and regional linkages in Vietnam, Proceedings of the national workshop: Innovation, motivation and policy for regional development - theory, experience and action, 2016.

21. Mariani, M. M. \& Kylanen, M. Cooperative and cooperative practices: Cases from the tourism industry, Plagrave Macmillan, N.Y, 2014.

22. Mills, J. E. \& Law, R. Handbook of consumer behavior, tourism and the internet, Haworth Hospitality Press, N.Y, 2004.

23. Ngo, T.L., and $\mathrm{Vu}, \mathrm{C}$. Linkage development and coordinating organization for linkage development of key economic regions in Vietnam, Political theory publisher, 2015.

24. Nguyen, V.H. Regional Linkage: From Theory to Practice. Finance Publishing House, Vietnam, 2012.

25. Nguyen, V.K., and Nguyen, T. Q. A. Regional and Sub-regional linkage in tourism development of the Northwest: From Theory to Practice, 2017, NEU Press.

26. Perroux, F. Note sur la notion de poles croissance, Economic Appliquee, 1955, 1\&2, 307-320.

27. Phu Tho People Committee, Summary document of Tourism Development Cooperation Program in 8 Northwestern Provinces expanded in 2016, 2017.

28. Pham, T. L. Development of Dien Bien tourism in association with Northwest region, Scientific Conference "Promoting the special value of Dien Bien Phu historical relics to promote Dien Bien tourism development in association with Northwest", March 13, 2014, Dien Bien Phu.

29. Plummer, M., Best, N., Cowled, K. \& Vines, K. CODA: Convergence diagnosis and output analysis for MCMC, R News, 6(1), 7-10. Publishing House of Political Theory, Vietnam, 2006.

30. Poon, A. The new tourism revolution, Tourism Management, 1994, 15(2), 91-92.

31. Saggi, K. \& Pack, H. Exporting externality and technology transfer, Policy Research Paper, World Bank, 1999.

32. Tran, H.S. Policy formulation linking the Northwest region and tourism region, Proceedings of the Conference on Science and Technology to promote the link and development of the Northwest, KHCN-TB/13-18 Program, Hoa Binh, Nov 2016.

33. Tran, D.T. Institute of regional cooperation and development cooperation - the determinant of regional development, Proceedings of international scientific seminars: Linkages in the process of economic restructuring and transformation of growth model in Vietnam Male, 2016.

34. Vu, T.B. Regional Economic Development - Issues and Solutions, Proceedings of the National Scientific Conference: Situation and Solutions for Regional and Sub-regional Integration in Tourism Development in the Northwest, Labor and Social Affairs House, 2017.

35. Wang, Y. \& Shaul, S. Destination marketing: competition, cooperation \& operation, International Journal of Contemporary Hospitality Management, 2008, 20(2), 126-141. 